\title{
EL GOLPE DE LA INJUSTICIA DISTRIBUTIVA DE LAS ÁREAS VERDES A LAS POBLACIONES MENOS FAVORECIDAS EN EL CONTEXTO DEL COVID-19
}

\author{
Andrea Tang Valdez \\ Investigadora independiente
}

\begin{abstract}
Resumen: El presente trabajo consta de tres partes. En la primera se introduce la necesidad de un estándar en metraje por habitante de área verde en las ciudades de Perú. Adicionalmente, que los sucesos como la pandemia por el Covid-19 pueden afectar a la población sobremanera debido al manejo de espacios públicos, específicamente las áreas verdes sin planificar. En la segunda parte se extiende una reflexión sobre la nueva tipología de rediseño de espacios verdes como respuesta ante la pandemia y prevención ante futuros escenarios que sometan a las poblaciones al aislamiento social obligatorio y como nueva mirada del concepto de desarrollo urbano sostenible. En la tercera parte se trata la afectación de las poblaciones, sobre todo las menos favorecidas, a situaciones de aislamiento social debido a la injusticia distributiva de las áreas verdes en las ciudades.
\end{abstract}

Palabras clave: área verde, aislamiento social, desarrollo urbano sostenible. 


\title{
The Impacts of Green Areas Distributive Injustice on Marginalized Population in the Context of Covid-19
}

\begin{abstract}
This paper has three sections. In the first section, I introduce the need of a standard in square meters green areas of cities in Peru. I explore how the Covid-19 pandemic can affect the population and public space management, specifically green areas built without any planification. In the second part I reflect on the new typology of green space redesign as a response to the pandemic and prevention for future scenarios that subject populations to mandatory social isolation. In the third part I refer to the affectation of the populations, especially the least favored situations of social isolation due to the distributive injustice of green areas in cities.
\end{abstract}

Keywords: Green area, Social isolation, Sustainable urban development.

\section{Andrea Tang Valdez}

Licenciada en Derecho y Magíster en Desarrollo Ambiental por la Pontificia Universidad Católica del Perú. Becaria del Environmental Sustainability Professional Fellowship Program del Departamento de Estado de los Estados Unidos de Norteamérica. Sub-directora de la Asociación Peruana de Actores para la Gestión de Residuos. Miembro del Grupo de Estudios Ambiente y Sociedad.

Correo: andreatangvaldez2@gmail.com 
La pandemia por el Covid-19 (Coronavirus Disease 2019, por sus siglas en inglés) ha promovido reflexiones sobre cómo se encuentran hoy diseñadas las ciudades y cómo podrían adecuarse ante otros posibles escenarios que involucren aislamiento social continuado. El enfoque de este análisis debe incluir las áreas verdes de las ciudades que permitan a los ciudadanos desplazarse y recrearse de manera segura. En este sentido, cabe analizar diferentes aspectos.

\section{1. ¿Existe un metraje de área verde adecuado y/o suficiente por habitante en la planificación de las ciudades? ¿Debemos pensar en un metraje adecuado de área verde por habitante en un contexto de pandemia?}

La definición más común de «espacio verde urbano» que ha sido utilizada en estudios en Europa está basada en el Código Atlas Urbano 14100: áreas verdes públicas predominantemente para recreación como jardines, zoológicos, parques y áreas naturales suburbanas, bosques y áreas rodeadas de áreas urbanas que son utilizadas para propósitos de recreación (Unión Europea 2011). Cabe resaltar que el concepto de áreas verdes difiere de país a país, por ello es difícil establecer qué es un área verde de manera estandarizada y, por tanto, poder realizar comparaciones (Banco Interamericano de Desarrollo 2016: 134).

En el Perú, el Sistema Nacional de Información Ambiental (2018) indica que «las áreas verdes son espacios compuestos con vegetación, sobre todo, pastos, árboles y algunos arbustos». La Ley № 26664, que dicta disposiciones referidas a la administración de las áreas verdes de uso público, en su artículo 1, establece que los parques metropolitanos y zonales, plazas, plazuelas, jardines y demás áreas verdes de uso público bajo administración municipal forman parte de un sistema de áreas recreacionales y de reserva ambiental con carácter de intangibles, inalienables e imprescriptibles.

Así, en Lima Metropolitana se cuenta con áreas que son consideradas como espacios verdes urbanos. De conformidad con el Anexo 1 de la Ordenanza № 1853, Ordenanza que establece los 23 principios de la estructura ecológica de Lima Metropolitana, de fecha 28 de diciembre de 2014:

Los espacios verdes públicos o áreas verdes urbanas, son sistemas estratificados por áreas verdes ornamentales y forestales, cuentan con subvención antrópica para proporcionar ornato verde, fuente de oxigeno y captador del $\mathrm{CO}_{2}$, paisaje de recreación y esparcimiento, 
belleza urbana, pulmón urbano. Están formadas por parques, jardines, alamedas, entre otras formas; constituidas por especies arbóreas, matorrales, herbáceas, flores, gramíneas, etc. Son también refugio de fauna adaptada a la ciudad (aves, mamíferos, reptiles, insectos).

Los espacios verdes ocupados principalmente por árboles, arbustos y herbáceas ornamentales o de cobertura, actúan como reguladores del equilibrio ambiental, son elementos representativos del patrimonio natural y garantizan el espacio libre destinado a la recreación, contemplación y ocio para todos los habitantes de la ciudad. La gestión del Sistema de Áreas Verdes se regulará conforme a su Ordenanza específica.

En relación a cuánto de área verde debe tener acceso un ciudadano, no existe fuente verificable que indique el metraje cuadrado de área verde por habitante como parámetro mundial. Muchos factores estarían envueltos, tales como humedad, precipitación, densidad poblacional, suelo, clima y otros. Cada espacio es diferente a otro, con lo cual definir un metraje cuadrado de área verde por habitante a nivel mundial también consideraría las características sociales, estructurales y de infraestructura de las diferentes ciudades. Además, las ciudades más populosas y concurridas serían aquellas que mayor dificultad encontrarían para llegar a la meta del metraje de área verde establecido globalmente.

La accesibilidad y proximidad a espacios verdes son factores importantes en la planificación de estos porque se considera que los ciudadanos tienen derecho a gozar de ellos. Por ejemplo, Gran Bretaña tiene estándares como accesibilidad a espacio natural verde con distancia menor de 300 metros contados desde las viviendas; el reglamento sobre reservas naturales locales, que indica que debe contarse con un mínimo de 1 hectárea por 1000 habitantes, establece al menos un sitio accesible de 20 hectáreas dentro de los 2 kilómetros de distancia a los hogares, un sitio accesible de 100 hectáreas dentro de 5 kilómetros contados desde hogares y un sitio accesible de 500 hectáreas dentro de 10 kilómetros contados desde hogares (Haq 2011: 604).

Por su parte, el Perú es un país que cuenta con diversas ciudades que han crecido de manera acelerada e improvisada debido a diferentes causas, como la migración, pobreza, centralización y falta de planificación urbana. Por cuanto no se guarda un orden en el crecimiento urbano que vincule los espacios verdes a la infraestructura de vivienda, comercios, oficinas u otros.

En el contexto de la pandemia por el Covid-19, el Robert Koch Institut de Alemania (2020) ha considerado diversas medidas para controlar y mitigar la expansión del virus, entre ellas: que las personas mantengan 1.5 metros de distancia entre una y otra cuando se encuentren en público; prohibición de apertura de restaurantes y negocios que congreguen personas presencialmente; prohibición de reunión de más de dos personas; y otras recomendaciones relativas al distanciamiento social en metraje dependiendo si las personas se encuentran caminando, corriendo o conduciendo bicicletas u otros vehículos.

En el Perú, la población ha experimentado confinamiento de más de tres meses, lo que la ha obligado a acomodar sus actividades. Con las nuevas medidas 
que flexibilizan el aislamiento social, algunos grupos de personas pudieron salir de sus hogares; por ejemplo, aquellos quienes realizan algún deporte o pasean a los niños en horarios determinados. Sin embargo, no todas las personas que habitan las ciudades tienen el privilegio de contar con áreas verdes cercanas a sus hogares; peor aún tratándose de las zonas menos favorecidas en el territorio del Perú.

Frente a esta problemática, el Covid-19 ha recordado forzosamente, tanto a tomadores de decisiones como a la población en general, que las ciudades necesitan de planificación urbana que considere espacios verdes para todos y cada uno de los ciudadanos que las habitan, sin distinción. A este respecto, las áreas verdes (como espacios públicos) fortalecen a la ciudadanía a través del encuentro social que genera intercambio entre diferentes personas de diversas condiciones. A través de este proceso de interacción se expresa el contenido político de la vida pública, la manera cómo se debaten y definen los asuntos de interés común y se ejerce la ciudadanía en la ciudad contemporánea (Ramírez 2007: 100). Este acercamiento reduce la brecha social y la comprensión del otro como un ser diferente que forma parte de la misma urbe. De este modo, se logra una ciudadanía con menos prejuicios y más sólida.

En consecuencia, es preciso analizar si las sugerencias establecidas no solo por el Robert Koch Institut de Alemania, sino también por expertos sanitarios, podrían aplicar al rediseño de espacios públicos, específicamente a áreas verdes, como parte de un programa de aseguramiento de la ciudadanía en contextos de pandemia y en el trabajo de promoción de ciudades sostenibles.

\title{
2. El golpe transformacional en el diseño de la ciudad
}

\begin{abstract}
Según las cifras de 1998, en Lima y Callao existen 2998 parques con una superficie total de 1367 hectáreas. Ello significa que cada habitante de la ciudad dispondría de aproximadamente $1.92 \mathrm{~m}^{2}$ de área verde; actualizando los datos al año $2004 \mathrm{y}$ considerando una población mayor a 8 millones de habitantes, esto representaría aproximadamente $1.70 \mathrm{~m}^{2}$ de área verde. En la práctica, sin embargo, numerosas áreas verdes son arenales, espacios abiertos sin vegetación o en estado de abandono por falta de recursos económicos para su habilitación (Programa de las Naciones Unidas para el Medio Ambiente 2012: 63).
\end{abstract}

De acuerdo a la data del Sistema Nacional de Información Ambiental del Ministerio del Ambiente (2018), existe una disparidad de superficie de área verde urbana por habitante según los distritos de Lima Metropolitana. Así, en el año 2018, en el distrito de Pachacamac se identificó $0.85 \mathrm{~m}^{2}$ de área verde urbana por habitante; mientras que en San Isidro $22.09 \mathrm{~m}^{2}$ y en Miraflores 13.84 $\mathrm{m}^{2}$ por habitante.

Bajo estas premisas es que ha sucedido la pandemia por el Covid-19, que ha traído como efecto que los Estados reorganicen sus ciudades para evitar el 
contacto entre persona y persona a fin de frenar la propagación del virus. Los lugares que se han visto más afectados en tráfico por el aislamiento social son los parques y jardines de las ciudades (van der Berg 2020).

La Ley № 26664 pone a disposición de las municipalidades distritales y provinciales la administración y organización de los parques y jardines que se encuentran en su circunscripción. De modo que la Ley Orgánica de Municipalidad, Ley № 23853, establece cómo las municipalidades asumen dicha administración y organización. En realidad, el estado de los parques y jardines administrados por las municipalidades depende de la disponibilidad de presupuesto que se reúne por arbitrios. En este sentido, siempre que las municipalidades cuenten con fondos que puedan ser invertidos en el mantenimiento de parques y jardines, $\mathrm{y} / \mathrm{o}$ mejoras o remodelaciones de los mismos, estos podrán ser ejecutables. Esta disponibilidad presupuestal debe estar acompañada de lineamientos para la remodelación y la implementación de una metodología que permita el acceso de espacios verdes para todos los ciudadanos.

En el Perú, el desarrollo de normativa ambiental referente a parques y jardines es incipiente y aún no existe normativa relativa a metraje cúbico por habitante, mínimo de proximidad de las personas a dichas áreas verdes u otros mecanismos o medidas en el diseño de la planificación urbana que pondere el acceso de estos espacios verdes para todos los habitantes, considerando sobre todo la condición socioeconómica de todos los ciudadanos y no un desarrollo urbano que solo beneficie a la minoría económicamente más favorecida. Lo que es indispensable para la búsqueda del cumplimiento de los Objetivos de Desarrollo Sostenible (ODS), en específico el objetivo 11 referido a lograr que las ciudades sean inclusivas, resilientes y sostenibles. En este camino, la pandemia por el Covid-19 coloca a prueba la capacidad de los Estados para ejecutar los ODS, considerando las dificultades preexistentes para dicho cumplimiento.

Analizar un rediseño de ciudad no solo a partir de la afectación del Covid-19, sino en adelante ante posibles brotes de otros tipos de virus y otras enfermedades que hagan que la propagación pueda ser más acelerada, es un reto. Máxime si la ciudad ha crecido de manera improvisada, no se facilitará una pronta reestructuración física.

En este sentido, la propuesta debe repensar las ciudades incluyendo en el análisis ciertas variables, además del rediseño de espacios verdes para recreo, como una nueva tipología para espacio público dedicada al criterio de salud (Honey-Roses et al. 2020); considerar que transformaciones temporales de espacios públicos tendrán vocación de permanencia; huertos urbanos como propuesta ante la escasez de áreas verdes; y promoción de áreas verdes privadas como respuesta a la falta de áreas verdes públicas. 


\section{El golpe a la población menos favorecida por las inequidades en la distribución de los espacios verdes}

En las ciudades prima más espacio verde en distritos en los que habitan ciudadanos de mayores ingresos económicos. En Lima, por ejemplo, el distrito de San Isidro llega a tener más de $17.78 \mathrm{~m}^{2}$ por habitante, mientras que otros distritos llegan al $1 \mathrm{~m}^{2}$ (Lima Cómo Vamos 2018: 28). Es así que, en la mayoría de distritos en Lima, los habitantes (sobre todo de escasos ingresos económicos que habitan en áreas menos favorecidas) se han visto afectados durante el periodo de aislamiento social establecido por el Decreto Supremo № 044-2020-PCM, «que declara Estado de Emergencia Nacional por las graves circunstancias que afectan la vida de la Nación a consecuencia del brote del Covid-19», y los decretos posteriores (Decreto Supremo N 051-2020-PCM, Decreto Supremo № 064-2020-PCM y Decreto Supremo № 075-2020-PCM) que amplían el estado de emergencia y distanciamiento social. La flexibilización de las medidas de aislamiento social, como la apertura para que niños puedan salir acompañados de sus padres a caminar al aire libre por treinta minutos a máximo quinientos metros contados desde el hogar donde habita el niño — conforme al Decreto Supremo № 083-2020-PCM-, no ha funcionado de la misma forma en todos los distritos, pues el acceso a áreas verdes es limitado en muchos de ellos y, más grave aún, además de no existir áreas verdes de recreación, no se dispone de espacios públicos para recreo. Lo mismo ha sucedido con las medidas dedicadas a personas que realizan deporte al aire libre, por cuanto no todos cuentan con acceso cercano a sus hogares para realizarlo.

Un enfoque en desarrollo urbano sostenible es la consideración de las pandemias en el nuevo paradigma de vivienda (Castillo 2020). Convenir en la reorganización de las viviendas aplicando un nuevo modelo que considere las epidemias es un tópico primordial. Buscar la equidad social urbana permite acercarnos a un modelo de justicia distributiva de los espacios verdes para el aseguramiento de la salud pública general y, específicamente, en contextos de pandemia.

Las realidades en cada país son diferentes. En aquellos en donde el tráfico en las pistas es bajo, se ha aprovechado estos espacios de tránsito vehicular para que los peatones puedan circular de manera espaciada de modo que el contacto entre uno y otro sea menor. Esto ha funcionado en lugares donde los residentes de unidades multifamiliares habitan espacios con escasas áreas verdes (Freeman y Eykelbosh 2020). Sin embargo, no se puede aplicar el mismo método para Perú, donde en las ciudades prima el embotellamiento, el transporte público ineficiente y el exceso de uso de automóviles para una persona.

Ante la pandemia por el Covid-19, se denota que el Gobierno puede flexibilizar medidas de aislamiento social, sin embargo, estas no pueden ni deben estar dirigidas a un solo grupo de la población. Por el contrario, un rediseño de la ciudad permitirá, ante posteriores epidemias, mantener un mayor control de la propagación de las enfermedades a través de flexibilización de medidas de aislamiento social que incluyan a toda la sociedad. 
Los proyectos para enverdecer la ciudad deben atender a las diferentes formas de equidad, las cuales se ubican en tres bloques: justicia como distribución, justicia como reconocimiento y justicia como participación (Anguelovski et al. 2020). Analizar qué espacio es justificado para una intervención de proyecto de enverdecimiento debe sustentarse sólidamente a fin de que a través de esta intervención no se promueva el desplazamiento de los residentes locales y la incorporación de personas con mayores recursos económicos a estos espacios, pues esto conlleva al encarecimiento de vivienda y servicios alrededor del área y, por tanto, a una nueva segregación de ciudadanos con menos recursos que ven la necesidad de desplazarse de sus propias viviendas a áreas menos favorecidas, con lo cual la supuesta solución promovería un efecto contraproducente.

\section{Reflexiones finales}

- En un contexto en el que el Estado no tiene la capacidad de hacerse cargo de las áreas verdes urbanas y el crecimiento de la ciudad hace difícil la tarea de reacomodar los espacios para crear áreas verdes accesibles a las personas, la alternativa podría ser la promoción de huertos urbanos municipales.

- En vista de que el crecimiento de edificaciones en las ciudades ha promovido la pérdida de espacios verdes privados, se debe incluir normas que promuevan estos al interior de estas edificaciones.

- La valorización de espacios verdes urbanos es necesaria porque contribuye a cuantificar el costo de la gestión en el mantenimiento. A su vez, promueve que los habitantes visualicen el valor real de estos espacios y consideren su mantenimiento, máxime en contextos de pandemia.

- La nueva tipología para la reacomodación de los espacios verdes ya existentes en las ciudades, que incluya los aspectos sanitarios, debe tomar en cuenta que ante la posible transformación no se promueva la movilización de los habitantes locales.

- Los espacios verdes urbanos públicos como parte integrante del espacio público urbano ofrecen un potencial para fortalecer el intercambio social y reducir la brecha entre ciudadanos de diversas condiciones. 


\section{Referencias}

Anguelovski, I. et al. (2020). Expanding the boundaries of justice in urban greening scholarship: Towards an emancipatory, antisubordination, intersectional, and relational approach. Annals of the American Association of Geographers, 110(6): 1-59. https://doi.org/10.1080/24694452.2020.1740579

Banco Interamericano de Desarrollo (2016). De ciudades emergentes a ciudades sostenibles. Santiago de Chile: ARQ.

Castillo, R. (julio, 2020). Desarrollo urbano y vivienda post pandemia. Conferencia virtual de la Federación Latinoamericana y del Caribe de asociaciones y exbecarios de Japón-FELACBEJA. Perú: APEBEJA.

Freeman, S. y Eykelbosh, A. (2020). Covid-19 and outdoor safety: Considerations for use of outdoor recreational spaces. National Collaborating Centre for Environmental Health. Vancouver.

Haq, S. (2011). Urban Green Spaces and an Integrative Approach to Sustainable Environment. Scientific Research. Journal of Environmental Protection, 2(5): 601-608. DOI: 10.4236/jep.2011.25069

Honey-Roses, J. et al. (2020). The Impact of COVID-19 on Public Space: A Review of the Emerging Questions. https://doi.org/10.31219/osf.io/rf7xa

Lima Cómo Vamos (2018). Evaluando la gestión en Lima y Callao. VIII Informe sobre resultados y calidad de vida. Lima: Lettera Grafica S.A.C.

Programa de las Naciones Unidas para el Medio Ambiente (2012). Proyecto Geo Ciudades: 10 años. http://www.pnuma.org/deat1/pdf/Geo_ Ciudades(1-147)WEB11 mayo.pdf

Ramírez, P. (2007). La ciudadanía, espacio de construcción de ciudadanía. Revista Enfoques, (8). Ciudad de México: UNAM.

Robert Koch Institut (2020). Coronavirus-2019. Daily Situation Report of the Koch Institute. https://www.rki.de/DE/Content/InfAZ/N/ Neuartiges_Coronavirus/Situationsberichte/2020-04-19-en.pdf?_blob=publicationFile

Sistema Nacional de Información Ambiental (2018). Indicador: Superficie de área verde urbana por habitante en Lima Metropolitana. https://sinia.minam. gob.pe/indicador/998

Unión Europea (2011). Mapping Guide for a European Urban Atlas. Copenhague: Agencia Ambiental Europea.

Van der Berg, R. (2020). How will Covid 19 affect urban planning? The City Fix. https:// thecityfix.com/blog/will-covid-19-affect-urban-planning-rogier-van-den-berg/ 